\title{
Effectiveness of Push-Pull Systems to Fall Armyworm (Spodoptera frugiperda) Management in Maize Crops in Morelos, Mexico
}

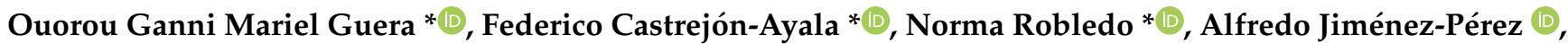 \\ Georgina Sánchez-Rivera, Lilia Salazar-Marcial and Hilda Elizabet Flores Moctezuma
}

Citation: Guera, O.G.M.; Castrejón-Ayala, F.; Robledo, N.; Jiménez-Pérez, A.; Sánchez-Rivera, G.; Salazar-Marcial, L.; Flores

Moctezuma, H.E. Effectiveness of Push-Pull Systems to Fall Armyworm (Spodoptera frugiperda) Management in Maize Crops in Morelos, Mexico. Insects 2021, 12, 298. https://doi.org/10.3390/insects 12040298

Academic Editor: Ezio Peri

Received: 18 February 2021

Accepted: 25 March 2021

Published: 29 March 2021

Publisher's Note: MDPI stays neutral with regard to jurisdictional claims in published maps and institutional affiliations.

Copyright: (C) 2021 by the authors. Licensee MDPI, Basel, Switzerland. This article is an open access article distributed under the terms and conditions of the Creative Commons Attribution (CC BY) license (https:/ / creativecommons.org/licenses/by/ $4.0 /)$.
Laboratorio de Ecología Química de Insectos, Centro de Desarrollo de Productos Bióticos, Instituto Politécnico Nacional, Calle CeProBi No. 8, San Isidro, 62739 Yautepec, Mexico; aljimenez@ipn.mx (A.J.-P.); gsanchezri@ipn.mx (G.S.-R.); lsalazarm@ipn.mx (L.S.-M.); hfloresm@ipn.mx (H.E.F.M.)

* Correspondence: gguerao1800@alumno.ipn.mx (O.G.M.G.); fcastrej@ipn.mx (F.C.-A.); nrobledo@ipn.mx (N.R.); Tel.: +52-735-394-2020 (F.C.-A.)

Simple Summary: Fall Armyworm (Spodoptera frugiperda) is an insect with generalist habits that causes serious damage to important agricultural crops, among which is maize (Zea mays). Given the obvious consequences of conventional agriculture and the limitations of organic agriculture, agroecological management strategies such as Push-Pull are increasingly considered since, in addition to production purposes, these systems channel economic, ecological, and social viability of that production. The successful introduction of these systems, still little implemented outside Africa, necessarily requires field effectiveness studies of laboratory and/or greenhouse proposals. Therefore, this study evaluated the field effectiveness of Push-Pull strategies designed for the management of S. frugiperda in maize crops in Morelos, Mexico. Most of the evaluated systems presented lower levels of fall armyworm infestations than those of the maize monoculture. Mombasa-D. ambrosioides, Mulato II-T. erecta, Mulato II-C. juncea, Tanzania-T. erecta and Tanzania-D. ambrosioides systems presented higher yields and profits than those observed in monocultures.

Abstract: Chemical control is the main method used to combat fall armyworm in maize crops. However, its indiscriminate use usually leads to a more complex scenario characterized by loss of its effectiveness due to the development of resistance of the insect pest, emergence of secondary pests, and reduction of the populations of natural enemies. For this reason, efforts to develop strategies for agroecological pest management such as Push-Pull are increasingly growing. In this context, the present study was carried out to evaluate field effectiveness of Push-Pull systems for S. frugiperda management in maize crops in Morelos, Mexico. In a randomized block experiment, the incidence and severity of $S$. frugiperda, the development and yield of maize were evaluated in nine Push-Pull systems and a maize monoculture. The Push-Pull systems presented incidence/severity values lower than those of the monoculture. Morphological development and maize yield in the latter were lower than those of most Push-Pull systems. Mombasa-D. ambrosioides, Mulato II-T. erecta, Mulato II-C. juncea, Tanzania-T. erecta and Tanzania-D. ambrosioides systems presented higher yields than those of monocultures.

Keywords: agroecology; attractive plants; repellent plants; sustainability

\section{Introduction}

Agroecological production systems are biodiverse, resilient, energy efficient, socially just and constitute a basis for food security and sovereignty [1,2]. In Latin America, including Mexico, a polyculture traditionally made up of maize (Zea mays L.), beans (Phaseolus vulgaris L.) and squash (Cucurbita spp.) that meets these characteristics is the Milpa [3]. This system, in addition to promoting agroecological and cultural diversity [4], 
is resistant to pests and diseases [5]. However, as part of agriculture sedentarization, the traditional milpa (of a migratory nature) is being replaced, even among small farmers and indigenous peoples, by a modern semi-permanent agriculture. In this context, it is necessary to implement semi-permanent agricultural systems that maintain the Milpa system benefits and are resistant to Spodoptera frugiperda, the major pest of maize in Mexico.

Among the agroecological production systems most adopted today, Push-Pull systems stand out [6-9]. The term Push-Pull arises from the pioneering studies of Pyke et al. [10] and Miller and Cowles [11]. The proposal made by these studies, despite their effectiveness, was not widely implemented due to various factors, including the high tolerance to the use of agrochemicals at that time. The most effective and therefore most widely implemented Push-Pull method is that developed by Khan et al. [12] in Kenya to combat Chilo partellus and Striga hermonthica in maize crops. This system, in addition to controlling the pest (C. partellus) and weeds (S. hermonthica), improves the soils, allows the production of other resources (forage) and doubles maize yield. The consideration of these additional goals took the Push-Pull to another dimension, making it an attractive agroecological management method and not just one of pest control.

Although this strategy is being widely adopted in many African countries, its implementation is still scarce outside the limits of that continent. The success of the Push-Pull system depends on the components (attractants and repellents) of the system that vary depending on the pathosystem, environmental factors, and the biotic and abiotic resources available in a certain region. For this reason, for the Zea mays-Spodoptera frugiperda pathosystem, in which Push-Pull has been shown to be efficient in Africa [13-15], studies were recently carried out with local and/or naturalized species [16]. The results of this study indicate that Brachiaria hybrid cv Mulato II, Panicum maximum cv Mombasa, Panicum maximum cv Tanzania could be suitable trap plants and Dysphania ambrosioides, Tagetes erecta and Crotalaria juncea suitable intercrops in Push-Pull systems for S. frugiperda management in maize crops in Morelos, Mexico. However, the field effectiveness of these has not been evaluated.

Based on the above, the present study was carried out to evaluate the field effectiveness of these local Push-Pull variants for the management of S. frugiperda in maize crops in Yaupetec, Morelos, Mexico.

\section{Materials and Methods}

\subsection{Study Area Characterization}

The present study was carried out in an area of $6341 \mathrm{~m}^{2}$ located in maize production areas of the Lomas del Potrero neighborhood, Yautepec municipality, Morelos state, Mexico, with geographic coordinates between $18.893323 \mathrm{~N}$ and $99.102158 \mathrm{~W}$ (Figure 1). Yautepec has a tropical savanna climate (Aw), according to the Köppen-Geiger classification, an annual rainfall of $928 \mathrm{~mm}$ and an average temperature of $23.2^{\circ} \mathrm{C}$ [17]. The temperature and relative humidity of the area (Figure 2) were monitored throughout the experiment (20 June 2019-16 December 2019) with a Lascar EL-USB-2 datalogger (Accuracy: $\pm 0.45^{\circ} \mathrm{C} / \pm 2.05 \%$ $\mathrm{RH})$ programmed for a recording frequency of $10 \mathrm{~min}$. During the experimental period, the area presented an average temperature of $23.69 \pm 1.55^{\circ} \mathrm{C}$ and average relative humidity of $74.90 \pm 4.94 \%$. 


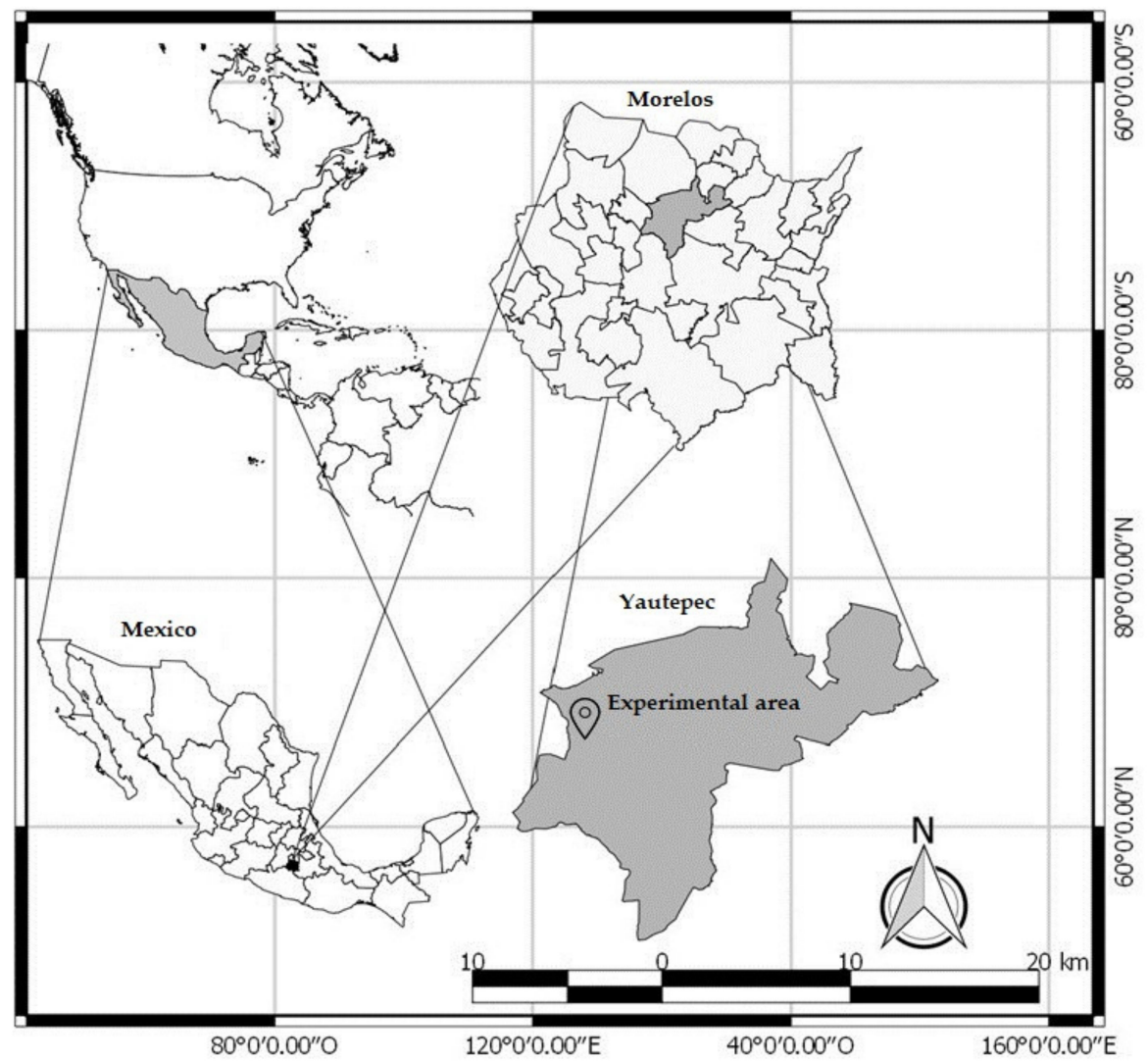

Figure 1. Location of the study area, Municipality of Yautepec, Morelos, Mexico.

A Daily temperature

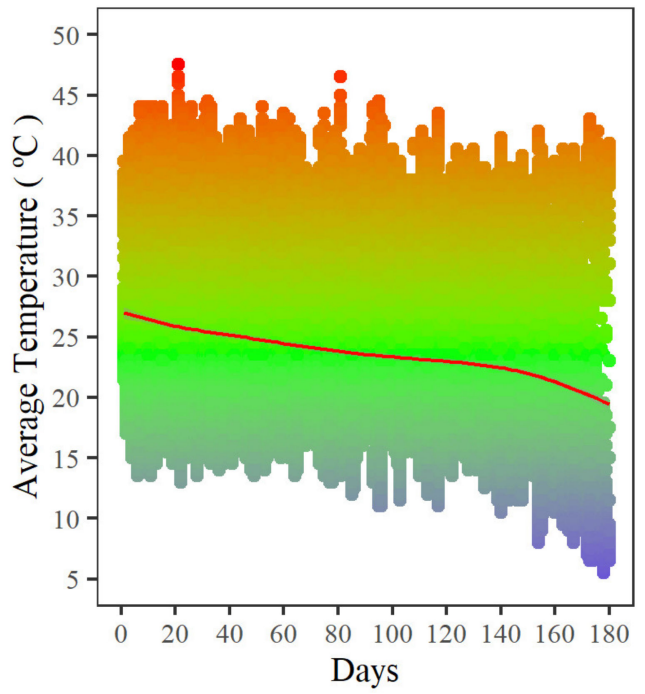

B Daily relative humidity

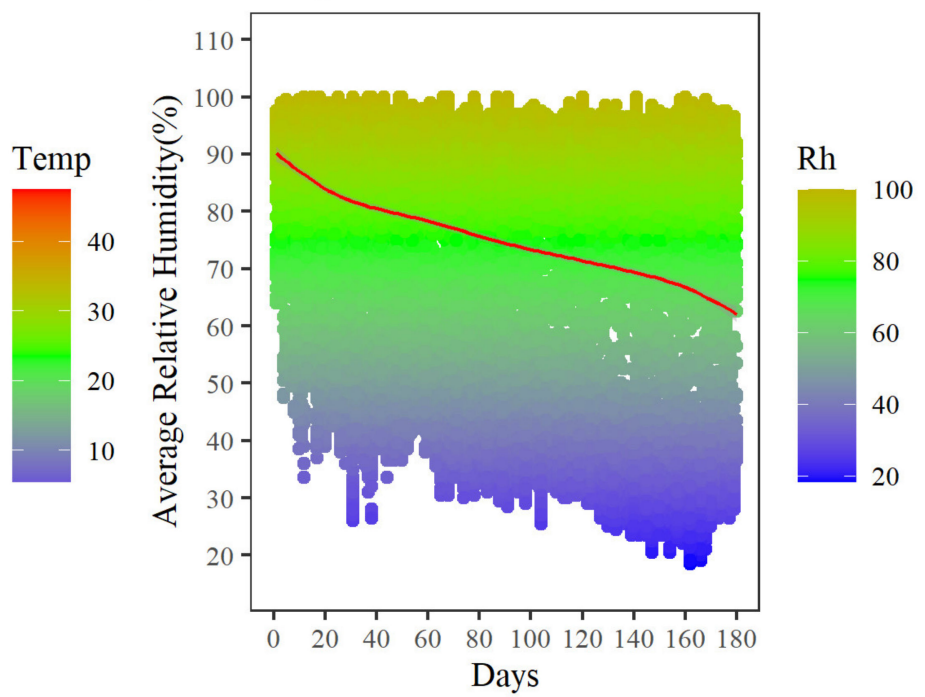

Figure 2. Evolution of temperature and relative humidity during the experiment at Yautepec Municipality, Morelos, Mexico.

\subsection{Experimental Design}

Ten treatments (Table 1 ) were evaluated in experimental units $(14 \mathrm{~m} \times 14 \mathrm{~m}$ plots) made up of 8 beds ( $1.06 \mathrm{~m}$ wide and $10 \mathrm{~m}$ long) established in a randomized complete block design (Figure 3A). This design accounted for the fertility gradient observed in the experimental area and the size of the plots was chosen to comply with the minimum size of $10 \mathrm{~m} \times 10 \mathrm{~m}$ recommended by Khan [18] for Push-Pull plots. 
Table 1. Fall armyworm management systems tested in maize crops in Yautepec, Morelos, Mexico.

\begin{tabular}{|c|c|c|c|}
\hline \multirow{2}{*}{ System Codes } & \multicolumn{2}{|c|}{ Components } & \multirow{2}{*}{ Treatments } \\
\hline & Attractants $¥$ & Intercrops * & \\
\hline MIIC & \multirow{3}{*}{ Brachiaria hybrid cv Mulato II } & Crotalaria juncea & Mulato II \& C. juncea \\
\hline MIIT & & Tagetes erecta & Mulato II \& T. erecta \\
\hline MIID & & Dysphania ambrosioides & Mulato II \& D. ambrosioides \\
\hline $\mathrm{MC}$ & \multirow{3}{*}{ Panicum maximum cv Mombasa } & Crotalaria juncea & Mombasa \& C. juncea \\
\hline MT & & Tagetes erecta & Mombasa \& T. erecta \\
\hline MD & & Dysphania ambrosioides & Mombasa \& D. ambrosioides \\
\hline $\mathrm{TC}$ & \multirow{3}{*}{ Panicum maximum cv Tanzania } & Crotalaria juncea & Tanzania \& C. juncea \\
\hline $\mathrm{TT}$ & & Tagetes erecta & Tanzania \& T. erecta \\
\hline $\mathrm{TD}$ & & Dysphania ambrosioides & Tanzania \& D. ambrosioides \\
\hline M & - & - & $\begin{array}{l}\text { Maize monoculture not } \\
\text { treated with pesticides }\end{array}$ \\
\hline
\end{tabular}

Source: Guera et al. [16]; ${ }^{¥}$ trap plants established at a distance around the main crop; * plants intercropped in the main crop.

(A)

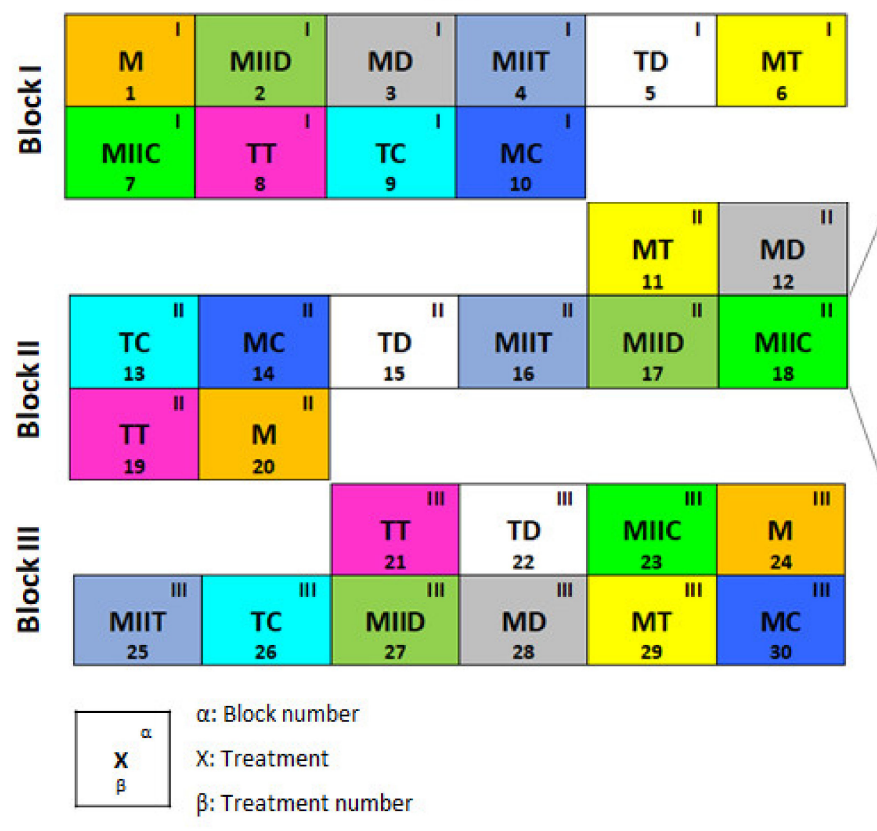

(B)

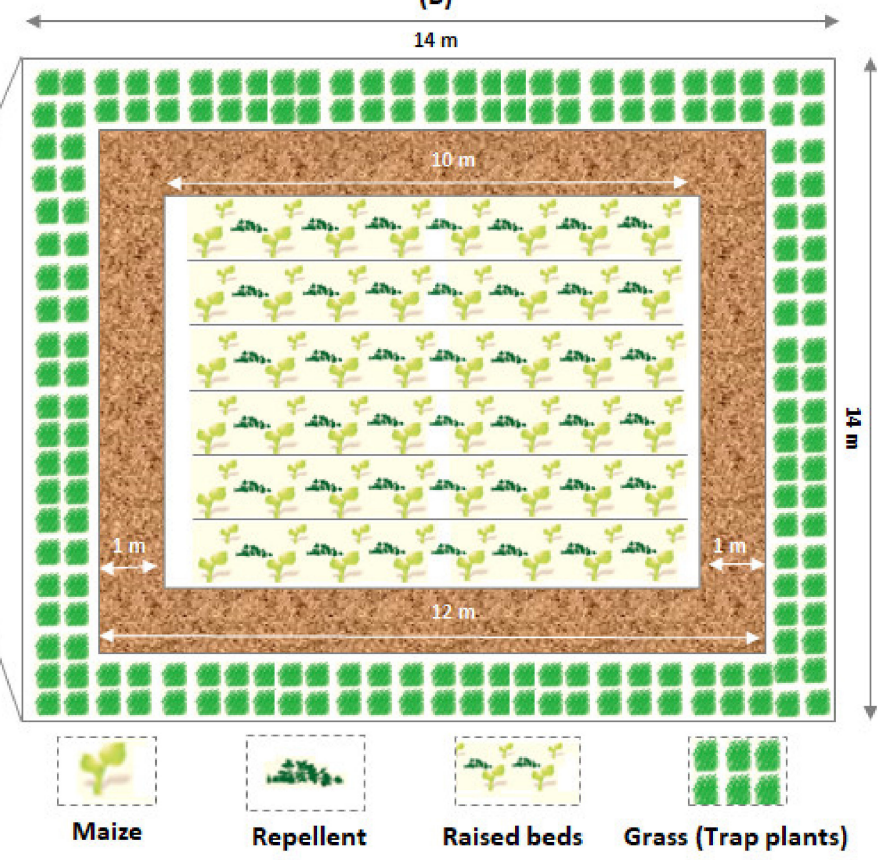

Figure 3. Experimental units (B) established in a randomized block experiment (A). For abbreviations, see Table 1.

In each of the experimental units equidistant of $2 \mathrm{~m}$ in each block, the maize planting area $(10 \mathrm{~m} \times 10 \mathrm{~m})$ was made up of 6 beds of maize (Pioneer P3966W) as the main crop and an intercrop (repellent). At one meter from the maize planting area of each plot, a grass border (Fall armyworm trap plant) was established (Figure 3B). The plots establishment data are summarized in the Table S1. All treatments presented weed infestation, which was controlled manually every fifteen days until canopy closure in each plot.

\subsection{Incidence and Severity of Spodoptera Frugiperda Damage}

In each plot, samplings were carried out at 7, 14 and 21 days after maize germination (DAG) with the five-point sampling method, checking 10 plants at each point (Figure S1). The number of damaged plants was used to determine the incidence (Equation (1) - [19]). Severity was evaluated by visual observation of the degree of leaf damage. For this, a severity scale made up of five categories was used [13,15]: 1. damage-free plants (plants without visual symptoms of damage); 2 . plants with low damage (plants with leaf area 
damage less than $25 \%$ ); 3. plants with medium damage (plants with leaf area damage between 25\% and 50\%); 4 . plants with high damage (plants with leaf area damage between $50 \%$ and $75 \%$ ); and 5 . plants with very high or severe damage (plants with more than $75 \%$ of their leaf area damaged). Unlike the incidence that was evaluated once a week during the crop's first three weeks, the severity (Equation (2) - [19]) was only evaluated in the third week after maize germination (at 21 days).

$$
\begin{gathered}
I(\%)=\frac{N D P}{N P E} * 100 \\
S(\%)=\frac{\sum N P D D * D D}{N P E * G D D} * 100
\end{gathered}
$$

where: $I=$ Incidence; $N D P=$ Number of damaged plants; $N P E=$ number of plants evaluated; $S=$ severity; $N P D D=$ number of plants damaged to a certain degree of damage; $D D=$ degree of damage; $G D D=$ greater degree of damage.

The percent reduction of Fall Armyworm damage by Push-Pull systems over the control (monoculture) was determined by Equation (3) [20].

$$
P R=\frac{(C-P P S)}{C} \times 100
$$

where: $P R$ is the percent reduction of Fall Armyworm incidence (FAIR) or severity (FASR) over monoculture; $C$ is Fall Armyworm incidence or severity in the control (monoculture) and PPS is Fall Armyworm incidence or severity in one of the Push-Pull systems.

\subsection{Morphoagronomic and Edaphoclimatic Variables in the Production Systems}

Mixed cropping can affect maize crops' growth. Therefore, after the vegetative phase, approximately three months after the establishment of the crops, stem diameter (Dt), total height (Ht), cob diameter (De) and cob length (Le) were measured in ten plants selected at random in each treatment. Leaf Area Index-Equation (4) [21] was determined in each of the systems using the Beer-Lambert absorption law [22]. Measurements of transmitted and incident photosynthetically active radiation (RFAt y RFAi) were made with a digital meter ( ${ }^{\circledR}$ Steren) at 65 days of cultivation, in the center of each plot, between 12:00 p.m. and 2:00 p.m.

$$
L A I=-\frac{\operatorname{Ln}\left(\frac{I}{I_{0}}\right)}{k}
$$

where: $L A I=$ Leaf Area Index; $k=$ light extinction coefficient $\sim 0.60 ; I=$ transmitted photosynthetically active radiation (over the canopy); $I_{0}=$ incident photosynthetically active radiation (below canopy).

The sustainability of an agroecosystem depends on efficient water management [2]. Therefore, soil moisture and temperature were measured after canopy closure in the plots, after a canicular period of approximately 2 weeks. Soil moisture was measured with a Kelway meter (Accuracy: $\pm 10 \%$ ) and soil temperature with a thermometer ${ }^{\circledR}$ Taylor (depth: $13 \mathrm{~cm}$; Accuracy: $\pm 2^{\circ}$ ). Five measurements of these variables were made in each plot, following the five-point sampling method (Figure S1).

\subsection{Maize Grains and Green Forage Yields in the Systems}

Maize grain yield was determined by manually harvesting two beds in each plot [23]. The cobs were shelled with a mechanical sheller and weighed with a hanging digital scale. At 153 and 168 days after maize germination, the moisture content of the grains was determined with an electric meter $\left({ }^{\circledR}\right.$ AGROFARM DK-6064). The harvest was carried out in the sixth month (December 16) with approximately a moisture content of $15 \%$ and the yields were adjusted to $14 \%$. The main dates of establishment of the experiment and maize harvest are shown in Table S1. 
The yield of $C$. juncea was determined by harvesting the production of the central bed $(1 \mathrm{~m} \times 10 \mathrm{~m})$ from each of the 9 plots that make up this species. Regarding the pastures (Mombasa, Tanzania, Mulato II), their yield was determined by the quadrant method, which consisted of cutting and weighing all the grass within a $1 \mathrm{~m}^{2}$ quadrat [24]. A sample was taken in each of the 9 plots of each grass species.

\subsection{Comparative Analysis of Profitability of the Production Systems}

The cost generated using a certain pest control technique must be less than the damage that the pest would cause if nothing were done [25]. Therefore, at harvest of maize, the profitability of each system (maize crop + Push-Pull strategy) was evaluated by the Net Present Value (NPV, Equation (5)) and the Benefit/Cost Ratio (BCR, Equation (6)), both estimated at a discount rate of $9.5 \%$ [26]. The costs and income considered for the determination of these criteria are summarized in Table S2.

$$
\begin{aligned}
& N P V=\sum_{t=0}^{n} \frac{B_{t}}{(1+r)^{n}}-\sum_{t=0}^{n} \frac{C_{t}}{(1+r)^{n}} \\
& B C R=\sum_{t=0}^{n} \frac{B_{t}}{(1+r)^{n}} / \sum_{t=0}^{n} \frac{C_{t}}{(1+r)^{n}}
\end{aligned}
$$

where: $C_{t}=$ Cost at the period $\mathrm{t} ; B_{t}=$ Benefit at the period $\mathrm{t} ; r=$ Discount Rate; $n=$ number of periods; $t=t$ th period (months).

\subsection{Statistical Analysis}

Data analyses were preceded by verification of compliance with the assumptions of normality and homoscedasticity for all the variables studied. These were verified with the Shapiro-Wilk [27] and Levene [28] tests, respectively. The analyses were carried out using mixed models, considering the treatments as fixed effects and the nested samples taken within each experimental plot as random effects. The analysis of variance of the variables that fulfilled the assumption of normality ( $\mathrm{Dt}, \mathrm{Ht}$, De, Le, LAI, soil temperature, soil moisture, maize grain yield and green forage yield) were carried out using Linear Mixed Model-LMM (Equation (7), [29]). The variables (incidence and severity) that did not meet this assumption were analyzed with a Generalized Linear Mixed Model-GLMM (Equation (8), [29]), using the Logit link function and the Beta error distribution model, as recommended by Chen et al. [30] for data in proportions or percentages. The LMM and GLMM models were fitted, respectively, with the lmer () and glmer () functions of the lme4 package [31]. Pairwise comparisons of means were carried out with the Scott-Knott [32] test performed using the ScottKnott package [33]. This test, in addition to being robust to non-compliance with normality assumption [34], is appropriate when there is interest in separating groups of means, without ambiguity in the results, in experiments with a large number of treatments [35].

$$
E\left[Y_{j} \mid u_{i}, \ldots, u_{q}\right]=\beta_{0}+\sum_{i=1}^{p} \beta_{i} x_{i j}+\sum_{k=1}^{q} z_{k j} u_{k}, j=1, \ldots, n
$$

where: $Y_{j}$ is a response variable with normal distribution, $\beta_{i}$ is the $i$ th fixed-effect coefficient, $x_{i j}$ is the $i$ th fixed-effect explanatory variable for the $j$ th observation, and $z_{k j}$ is the binary indicator variable for the effect of the $k$ th random effect, $u_{k}$, on the $j$ th observation.

$$
\left.\eta_{i j}=\right\}\left(E\left[Y_{j} \mid u_{i}, \ldots, u_{q}\right]\right)=\beta_{0}+\sum_{i=1}^{p} \beta_{i} x_{i j}+\sum_{k=1}^{q} z_{k j} u_{k}, j=1, \ldots, n
$$

where: $Y_{j}$ is a response variable whose conditional distribution given the random effects belongs to the exponential family or can be written as a quasi-likelihood, where $\beta_{0}$ is the overall mean, $\beta_{i}$ is the $i$ th fixed-effect coefficient, $x_{i j}$ is the $i$ th fixed-effect explanatory 
variable on the $j$ th observation, $z_{k j}$ is the binary indicator variable for the effect of the $k$ th random effect, $u_{k}$, on the $j$ th observation, and $g(\cdot)$ is the link function relating the conditional mean of the response to the predictors.

The differences between the management systems were observed in the biplot of a principal component analysis (PCA) based on the variables studied in the systems. The PCA was performed with the function prcomp () of the package stats and the biplot was constructed with the function foiz_pca_biplot () of the package FactoMineR [36]. To calculate the profitability criteria, the FinCal package [37] was used. All statistical analyses were performed in R 4.0.2 [38].

\section{Results}

\subsection{Incidence and Severity of Fall Armyworm in the Evaluated Systems}

Significant differences were observed between S. frugiperda (Fall Armyworm (FAW)) incidence in the systems at 7, 14 and 21 days (Figure 4). During the three dates, the lowest incidences were recorded in the MIIC system and the highest in the monoculture.

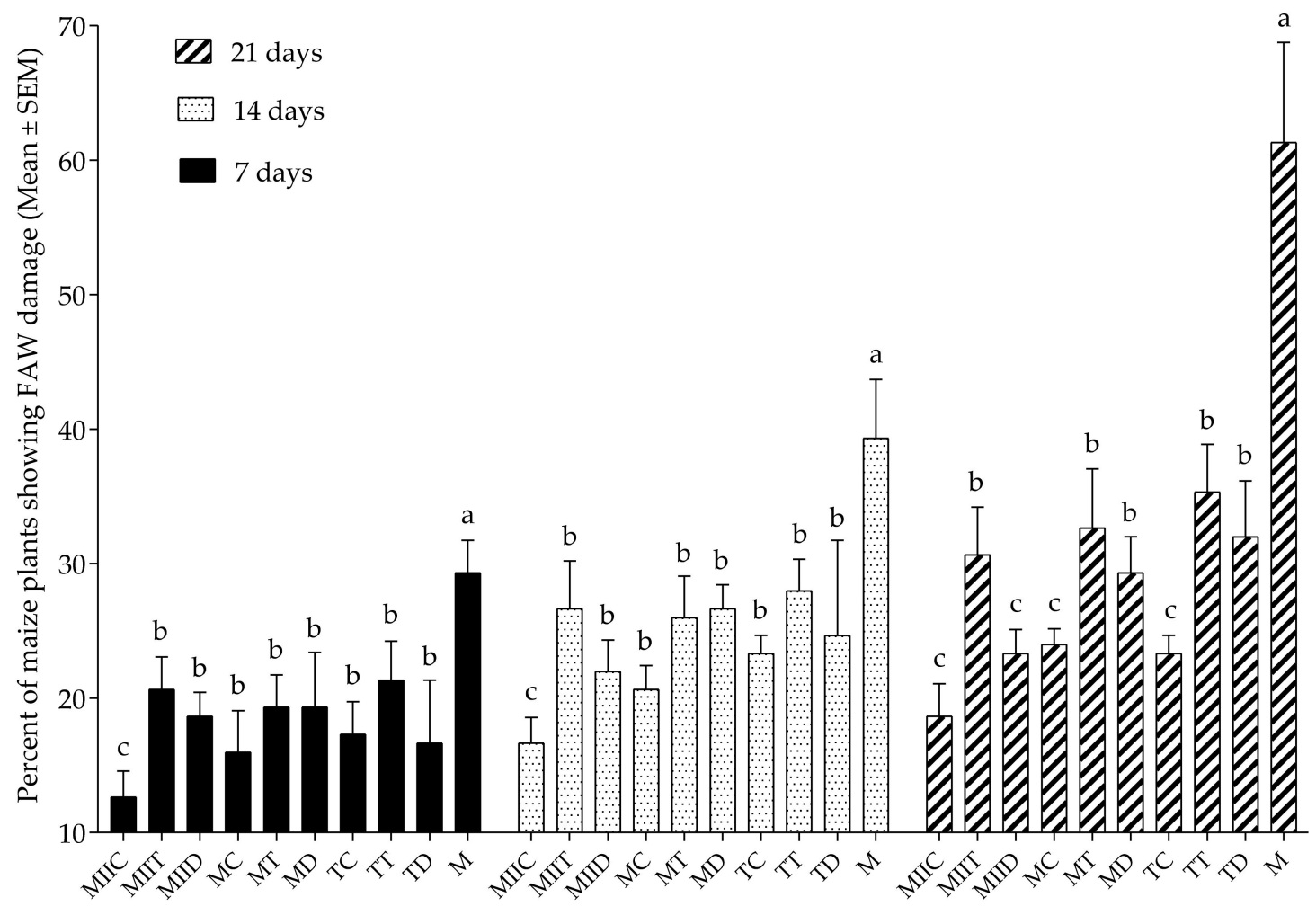

Figure 4. Incidence of $S$. frugiperda in maize crops in the systems evaluated at 7, 14 and 21 days. Different letters indicate a significant difference by the Scott-Knott test $(\alpha=0.05)$. For abbreviations, see Table 1.

This same trend is observed in Figure 5, which indicates that monoculture presented the lowest proportion of undamaged plants, and MIIC, MIID, TC and MC systems, the highest proportions. The monoculture presented the highest proportion of plants with high and severe damage (Figure $6 \mathrm{C}, \mathrm{D}$ ). The proportions of plants with low damage in the Push-Pull systems were significantly higher than those recorded in the maize monoculture (Figure 6A). 


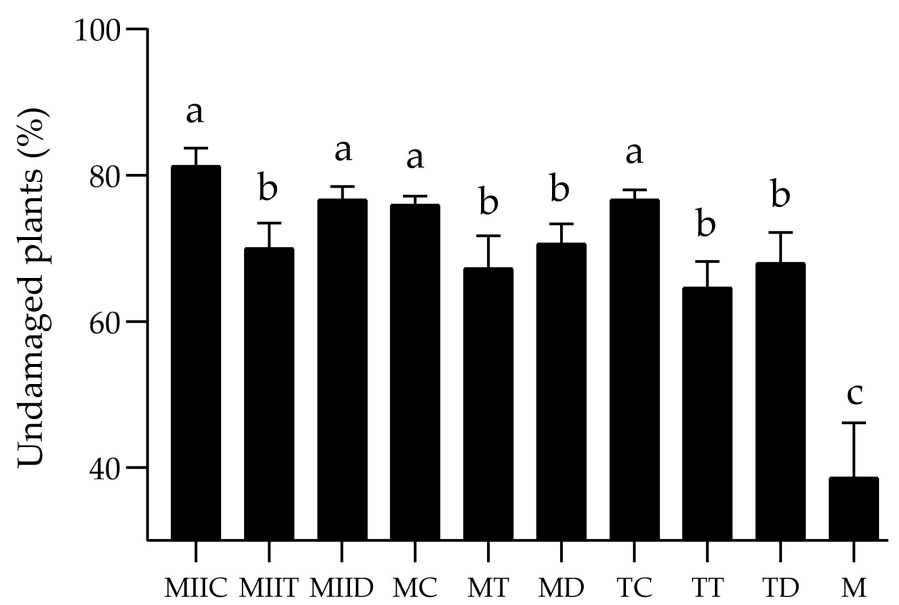

Figure 5. Percentage of undamaged plants in the different treatments. Different letters indicate a significant difference by the Scott-Knott test $(\alpha=0.05)$. For abbreviations, see Table 1.
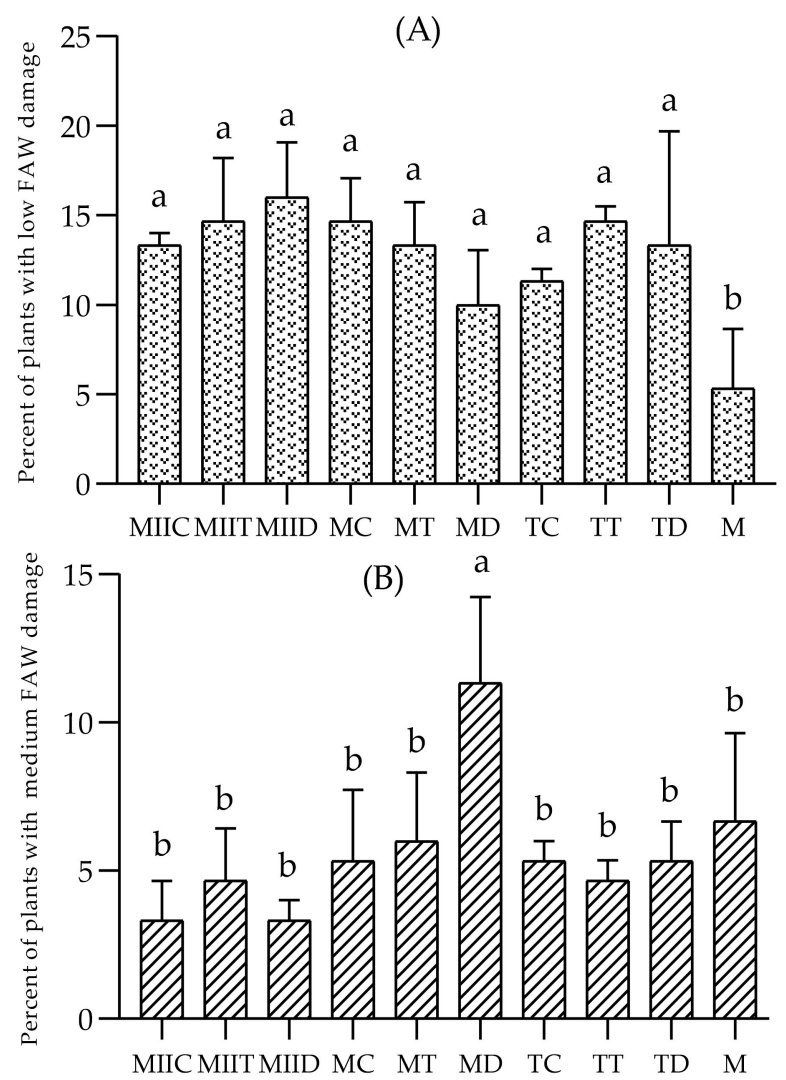

Figure 6. Cont. 


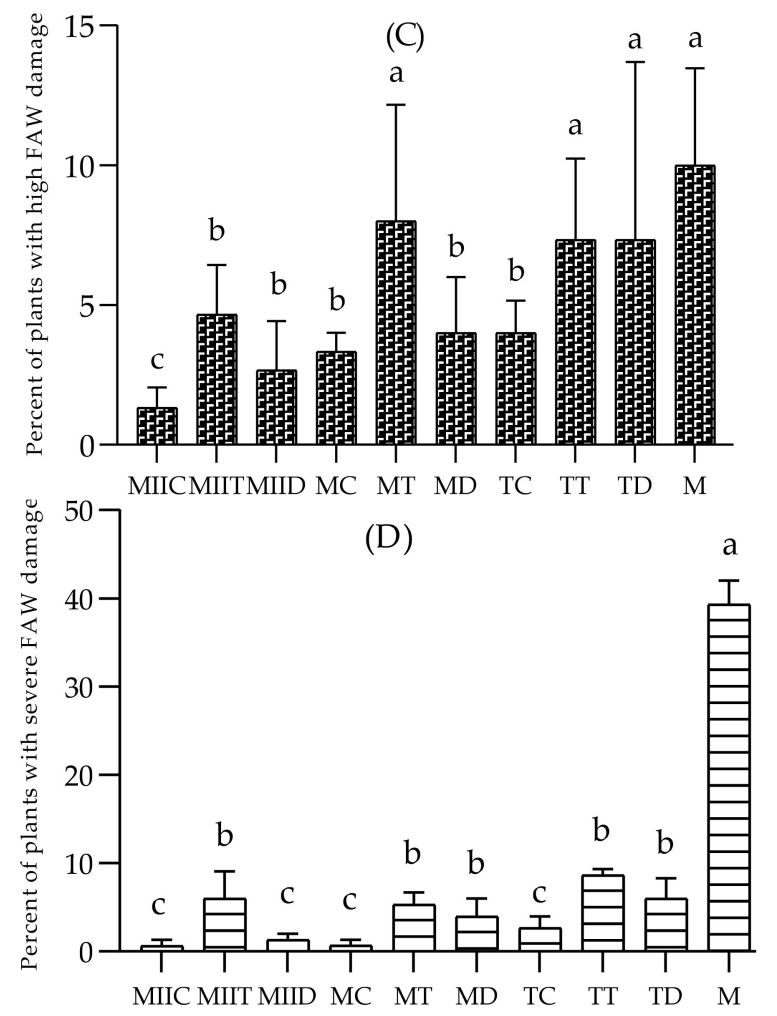

Figure 6. Severity of $S$. frugiperda in maize crops in the evaluated systems. Percent of plants with Fall Armyworm Low damage (A), Medium damage (B), High damage (C) and Severe damage (D). Different letters indicate a significant difference by the Scott-Knott test $(\alpha=0.05)$. For abbreviations, see Table 1.

\subsection{Morphoagronomic and Edaphoclimatic Variables in the Production Systems}

The results of the morphoagronomic variables comparison (Table 2) indicate that the maize crops did not develop evenly in the different management systems.

Table 2. Comparison of morphological variables in the evaluated systems.

\begin{tabular}{ccccc}
\hline Systems & $\begin{array}{c}\text { Stem Diameter } \\
(\mathbf{c m})\end{array}$ & $\begin{array}{c}\text { Total Height } \\
\mathbf{( m )}\end{array}$ & $\begin{array}{c}\text { Cob Diameter } \\
\mathbf{( c m})\end{array}$ & $\begin{array}{c}\text { Cob Length } \\
\mathbf{( \mathbf { c m } )}\end{array}$ \\
\hline MIIC & $2.43 \pm 0.11 \mathrm{a}$ & $2.54 \pm 0.04 \mathrm{a}$ & $5.40 \pm 0.21 \mathrm{a}$ & $24.22 \pm 0.77 \mathrm{a}$ \\
MIIT & $2.12 \pm 0.09 \mathrm{~b}$ & $2.43 \pm 0.03 \mathrm{a}$ & $5.03 \pm 0.17 \mathrm{a}$ & $22.65 \pm 0.40 \mathrm{~b}$ \\
MIID & $1.88 \pm 0.12 \mathrm{~b}$ & $2.28 \pm 0.06 \mathrm{~b}$ & $4.94 \pm 0.20 \mathrm{~b}$ & $22.50 \pm 0.49 \mathrm{~b}$ \\
MC & $2.09 \pm 0.11 \mathrm{~b}$ & $2.18 \pm 0.06 \mathrm{~b}$ & $4.65 \pm 0.18 \mathrm{~b}$ & $22.62 \pm 0.36 \mathrm{~b}$ \\
MT & $2.07 \pm 0.16 \mathrm{~b}$ & $2.22 \pm 0.07 \mathrm{~b}$ & $4.83 \pm 0.17 \mathrm{~b}$ & $22.43 \pm 0.49 \mathrm{~b}$ \\
MD & $2.06 \pm 0.11 \mathrm{~b}$ & $2.34 \pm 0.04 \mathrm{~b}$ & $5.28 \pm 0.18 \mathrm{a}$ & $23.22 \pm 0.43 \mathrm{a}$ \\
TC & $2.11 \pm 0.13 \mathrm{~b}$ & $2.45 \pm 0.03 \mathrm{a}$ & $5.13 \pm 0.12 \mathrm{a}$ & $22.60 \pm 0.37 \mathrm{~b}$ \\
TT & $2.42 \pm 0.17 \mathrm{a}$ & $2.40 \pm 0.07 \mathrm{a}$ & $5.35 \pm 0.21 \mathrm{a}$ & $23.39 \pm 0.44 \mathrm{a}$ \\
TD & $2.12 \pm 0.09 \mathrm{~b}$ & $2.53 \pm 0.04 \mathrm{a}$ & $5.43 \pm 0.12 \mathrm{a}$ & $23.72 \pm 0.50 \mathrm{a}$ \\
M & $1.69 \pm 0.19 \mathrm{~b}$ & $2.34 \pm 0.05 \mathrm{~b}$ & $4.51 \pm 0.23 \mathrm{~b}$ & $21.60 \pm 0.60 \mathrm{~b}$ \\
\hline
\end{tabular}

Means with different letters in a column indicate significant differences by Scott-Knott test $(\alpha=0.05)$. For abbreviations, see Table 1.

The plants with the largest diameters were recorded in the MIIC and TT systems, and those with the highest heights in the MIIC, TT, TD, MIIT and TC systems. The MIIC, TT and TD systems presented the largest maize cobs.

The systems also presented different Leaf Area Index (LAI), soil temperature and moisture (Figure 7). The Push-Pull systems presented similar LAI, which were significantly higher than that of the monoculture (Figure 7A). The highest moisture retentions were recorded in soils of systems with C. juncea as intercrop (Figure 7B). 

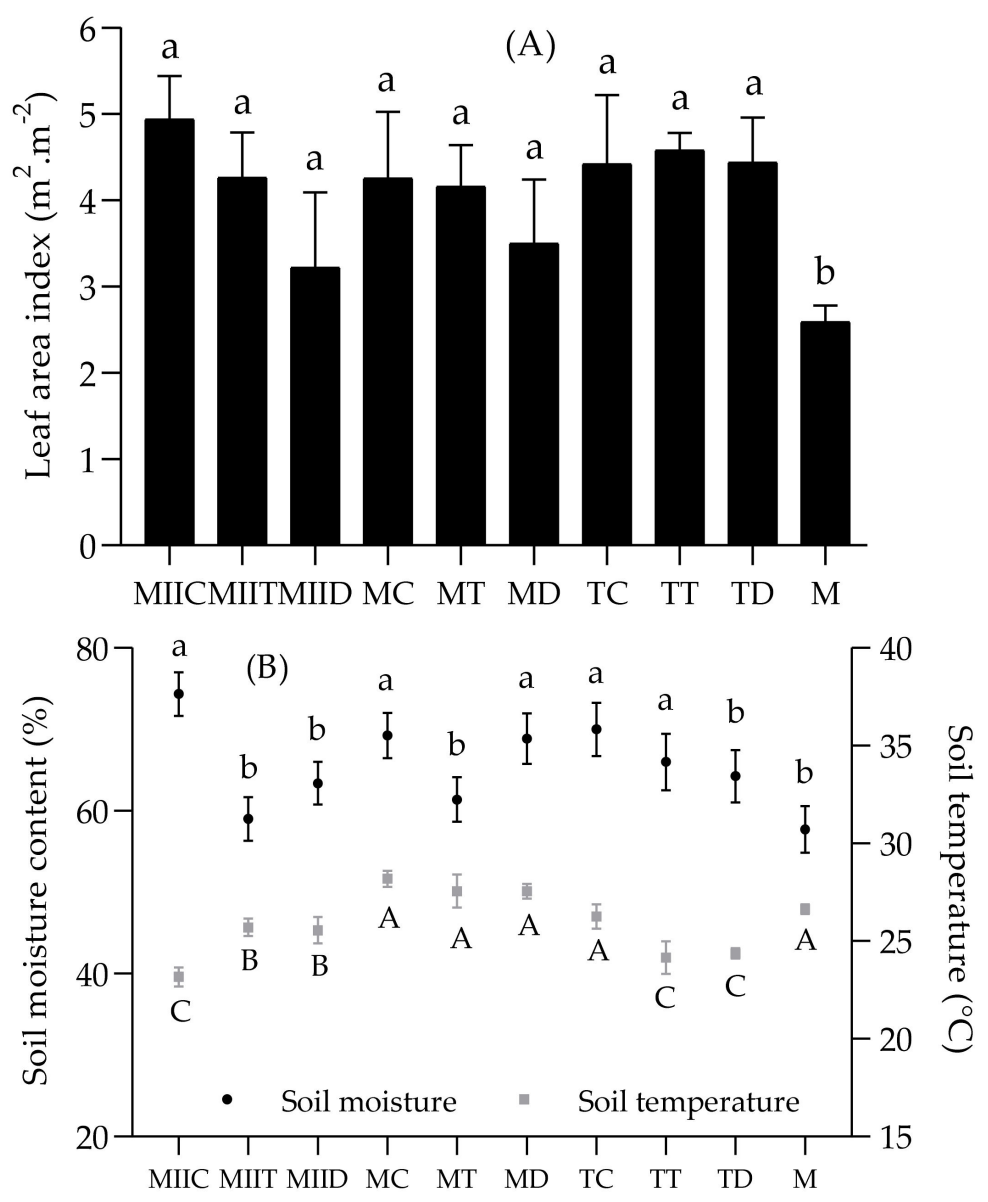

Figure 7. Comparison of Leaf Area Index (A) and soil moisture and temperature (B) in Push-Pull systems. Different letters indicate a significant difference by the Scott-Knott test $(\alpha=0.05)$. For abbreviations, see Table 1 .

\subsection{Maize and Forage Yields in the Production Systems}

Maize grain yields in the systems differed significantly. The lowest yields were observed in the $\mathrm{M}$ and $\mathrm{MC}$ systems (Figure 8). In relation to the forage grasses, there was a significant difference between their fresh yields. P. maximum cv. Mombasa $(54.44 \pm 3.77 \mathrm{t} / \mathrm{ha})$ and P. maximum cv. Tanzania $(55.56 \pm 4.03 \mathrm{t} / \mathrm{ha}$ ) presented similar yields, which were significantly higher than that of $B$. hybrid cv. Mulato II (41.11 $\pm 3.61 \mathrm{t} / \mathrm{ha})$. The only forage species among the intercropped crops (C. juncea) presented a fresh yield of $5.12 \pm 0.13 \mathrm{t} / \mathrm{ha}$.

The Kaiser criterion suggested the extraction of two main components. These two PCs explain $74.69 \%$ of the total variance of the variables. The first PC presented an eigenvalue of 1.64, responsible for $44.65 \%$ of the variance; the second PC presented an eigenvalue of 1.34 and explains about $30.04 \%$ of the total variance (Figure S2). Based on these two PCs, separations between the management systems were obtained (Figure 9). The relationship between monoculture performance with those of the Push-Pull systems for each of the aspects evaluated is summarized in Table 3. 


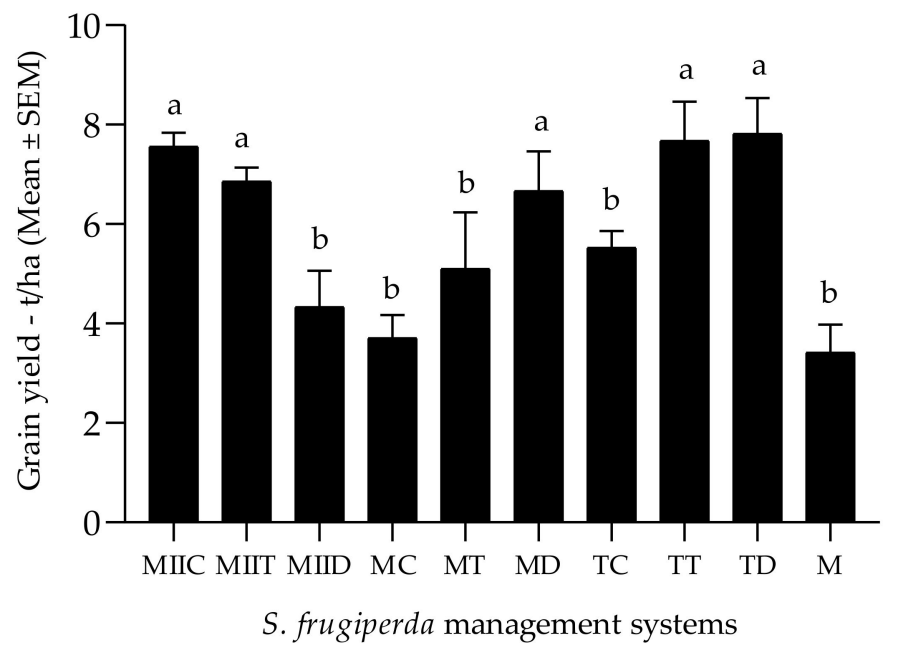

Figure 8. Maize grain yields (Mean \pm SEM) in the evaluated management systems. Different letters indicate significant difference $(p<0.05)$ by the Scott-Knott test $(\alpha=0.05)$. For abbreviations, see Table 1.

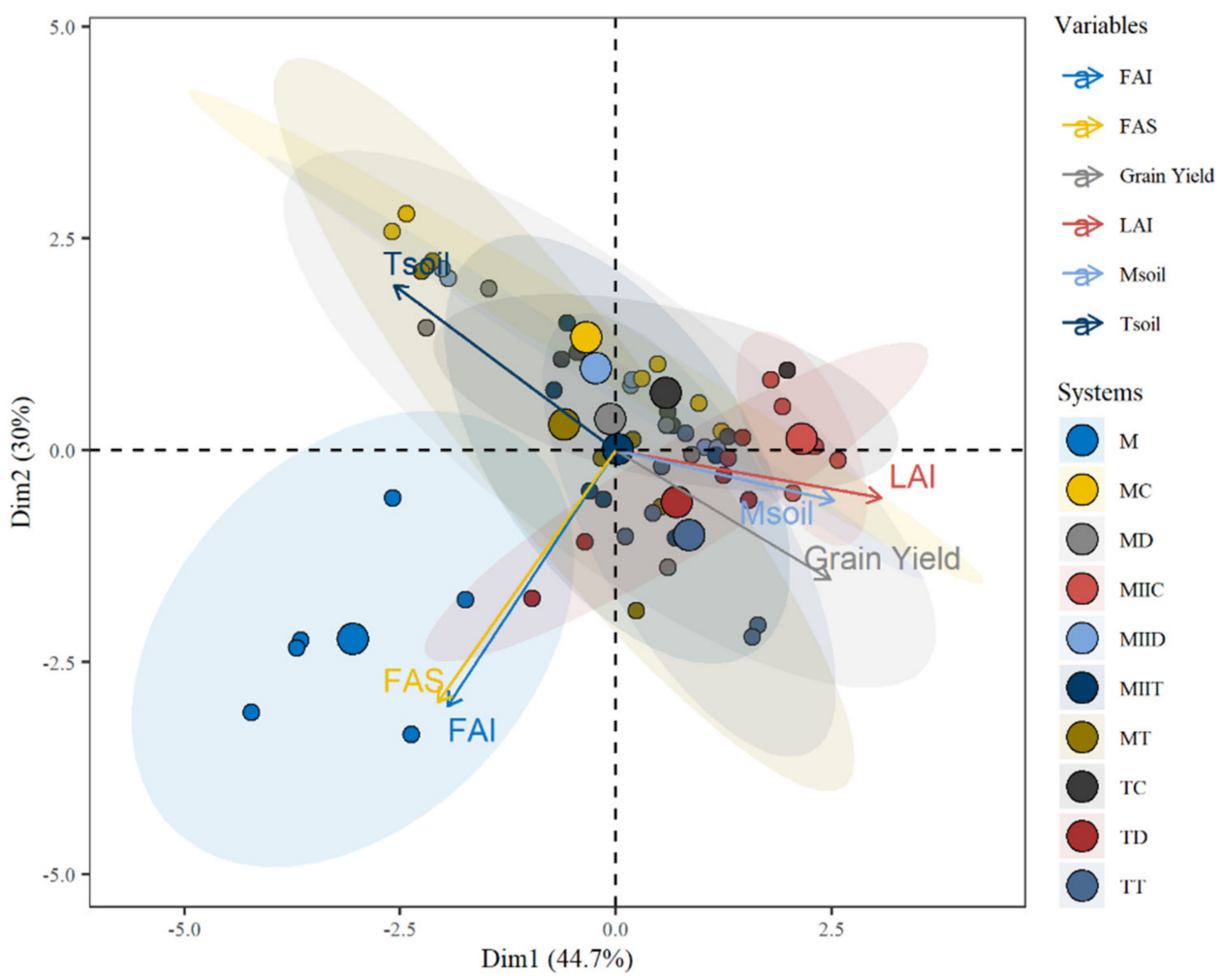

Figure 9. Biplot of principal component analysis based on variables studied in maize Push-Pull systems established in Yautepec, Morelos, Mexico. FAI = Fall Armyworm Incidence; FAS = Fall Armyworm Severity; LAI = Leaf Area Index; Msoil = Soil moisture; Tsoil $=$ Soil temperature. For abbreviations, see Table 1. 
Table 3. Comparison of the performances of Push-Pull systems and maize monocultures.

\begin{tabular}{ccccccc}
\hline \multirow{2}{*}{ System } & \multicolumn{2}{c}{ Phytosanitary, Edaphoclimatic and Yield Criteria } & \multicolumn{2}{c}{ Profitability Criteria } \\
\cline { 2 - 7 } & FAIR (\%) & FASR (\%) & ASMR (\%) & $\begin{array}{c}\text { PPY/MY } \\
\text { Ratio }\end{array}$ & $\begin{array}{c}\text { NPV } \\
\text { (\$ USD) }\end{array}$ & $\begin{array}{c}\text { Benefit/Cost } \\
\text { Ratio }\end{array}$ \\
\hline MIIC & 69.56 & 58.61 & 28.81 & 2.21 & 1012.924 & 2.62 \\
MIIT & 50.00 & 47.05 & 2.20 & 2.00 & 1065.394 & 1.90 \\
MIID & 61.97 & 55.56 & 9.82 & 1.27 & 727.265 & 1.41 \\
MC & 60.87 & 54.88 & 19.99 & 1.08 & 266.900 & 1.45 \\
MT & 46.74 & 44.23 & 6.36 & 1.49 & 745.613 & 1.65 \\
MD & 52.17 & 47.50 & 19.30 & 1.95 & 1238.939 & 1.71 \\
TC & 61.96 & 52.72 & 21.25 & 1.61 & 623.801 & 2.02 \\
TT & 42.39 & 40.95 & 14.33 & 2.24 & 1250.677 & 2.06 \\
TD & 47.83 & 44.45 & 11.33 & 2.28 & 1452.002 & 1.82 \\
\hline M & - & - & - & - & 518.703 & 1.59 \\
\hline
\end{tabular}

FAIR = Fall Armyworm Incidence Reduction; FASR = Fall Armyworm Severity Reduction; ASMR = Additional Soil Moisture Retention; PPY = Push-Pull Yield; MY = Monoculture Yield; NPV = Net Present Value; The conversion of dollar to Mexican peso used was: $\$ 1$ USD $=18.7018$ pesos (December 2019). For abbreviations, see Table 1.

\section{Discussion}

In this study, the field effectiveness of the Push-Pull systems proposed by Guera et al. [16] for S. frugiperda management in maize crops in the state of Morelos, Mexico, was evaluated. Push-Pull systems presented lower incidence (Figure 4) and severity (Figures 5 and 6) of fall armyworm, compared to monocultures. The greatest damage reductions were recorded in the MIIC system, which presented a reduction of $69.56 \%$ in FAW incidence and a reduction of $58.61 \%$ in its severity. These results concur with those of several field effectiveness studies (against Fall Armyworm) of the successful Push-Pull system designed by Khan et al. [12]. Midega et al. [13] and Khan et al. [14] reported reductions of 82.7\% in the average number of larvae per plant and $86.7 \%$ in the damage of plants per plot in the Push-Pull plots made up of Brachiaria cv Mulato II and Desmodium intortum (Mill.) Urb. Recently, Njeru et al. [39] reported a reduction of more than $50 \%$ of fall armyworm infestation in the same Push-Pull system. In the current study, the greatest reductions in Fall Armyworm incidence and severity were recorded in the MIIC, TC, MIID, MC, MIIT and MD systems (Table 3). The low incidence/severity values in all systems with the legume C. juncea (MIIC, TC, MC) coincide with the results of several studies. Among these are those of Hailu et al. [15], who reported a significant reduction in FAW incidence/severity in maize-legume inter-cropping. Altieri [40] also reported a significant reduction in FAW incidence in maize/beans intercropping.

The greater infestation of monocultures is reflected in the development of their crops. The results of morphoagronomic variables analysis indicates that the maize crops of the Push-Pull systems developed better than the monocultures (Table 2). The lower development of the latter and the existence of intercropping explain why the Push-Pull systems presented significantly higher LAIs (Figure 7A).

Most Push-Pull systems also outperformed monocultures in terms of maize grain yield (Figure 8), in the ratios of Table 3. This concurs with reports from Africa that PushPull (Pennisetum purpureum or Brachiaria cv Mulato II and Desmodium uncinatum) yields are 2 times higher than those of monocultures [13,41-43]. Improved yields in the Push-Pull systems are due to the reduction in the pest damage and moisture conservation of soil, among others [13]. The MC system maize crops showed poor vegetative development and low average yield, despite low levels of fall armyworm damage and optimal soil temperature and moisture levels. The average yield of this system was affected by its low yield in block III (2.05 t/ha). In that block (the least productive of the three), a high competition between maize and $C$. juncea was observed despite periodic pruning applied to C. juncea. The latter developed better than maize under these adverse conditions. For 
this reason, it is necessary that studies of optimal densities of $C$. juncea be carried out so that maize yield is not affected by the adoption of this system.

Most of the systems with the highest LAI presented high moisture content (MIIC, TT, TC, MC). Unlike Push-Pull systems, maize monocultures presented high soil temperature values and low soil moisture values (Figure 7B), explained by the greater exposure of their soils due to their smaller foliar surface. This concurs with Khan et al. [44], who cite soil moisture conservation and soil temperature reduction among the benefits of Push-Pull systems in Africa. This conservation of soil moisture is essential for the sustainability of agroecosystems [2].

C. juncea, the only legume of the intercropped species, in addition to fixing nitrogen, serves as green manure. For this reason, the leaves obtained from the periodic pruning applied to it were left on the floor of the plots for soil moisture conservation in the short term and their gradual incorporation into the soil as green manure in the medium or long term.

In the PCA biplot, the Push-Pull systems overlap, which indicates a certain degree of similarity between them. A separation of the monoculture from the Push-Pull systems is also observed (Figure 9). This is because, contrary to the Push-Pull systems, it presented a higher incidence/severity of fall armyworm, higher soil temperature, lower soil moisture content and lower maize grain yield.

The establishment costs of the Push-Pull systems were higher than those of monocultures. However, these costs were offset by the aggregate value of the companion crops. The NPV of all systems was positive and their benefit/cost ratio (BCR) greater than one. This indicates that these systems are economically viable, the most profitable being the systems TD, TT, MD, MIIT and MIIC. These systems, in addition to recovering the investment as in all systems, generated a minimum profit of 70 cents per dollar invested (Table 3). It is also perceptible that these systems, except for MIIC, were the ones that, in addition to presenting high maize yields, generated additional income from the accompanying crops, mainly T. erecta and D. ambrosioides, which have higher aggregate values than $C$. juncea. The MC system was one of the least profitable and this is because, in addition to presenting a lower maize yield, as previously discussed, it has a companion crop with lower aggregate value. A significant reduction in the costs of establishing the Push-Pull systems is expected in subsequent production cycles, like those reported by Khan et al. [45]. This will make these systems more attractive to maize producers and could favor their mass adoption.

\section{Conclusions}

In most of the Push-Pull systems evaluated, the maize crops developed adequately and those with the highest vegetative cover (LAI) presented a greater soil moisture conservation.

S. frugiperda incidence and severity in the Push-Pull systems were significantly lower than those observed in monocultures, with Mulato II-C. juncea, Mulato II-D. ambrosioides, Tanzania-C. juncea and Mombasa-C. juncea the ones that best controlled the pest.

The highest maize grain yields and profits were obtained in the Mombasa-D. ambrosioides, Mulato II-T. erecta, Mulato II-C. juncea, Tanzania-T. erecta and Tanzania-D. ambrosioides systems.

Supplementary Materials: The following are available online at https:/ /www.mdpi.com/article/10 .3390/insects12040298/s1, Table S1: Data of the establishment of the field experiment in the 2019 maize season (Experimental period: June-December 2019). Table S2. Costs and incomes considered for the profitability analysis of the production systems. Figure S1. Five-point sampling method used in the maize plots $(10 \times 10 \mathrm{~m})$ of the different production systems. SP = Sampling Point. Figure S2. Scree plots of eigenvalues (A) and cumulative variance explained (B) of principal components of Push-Pull systems evaluation variables at Yautepec, Morelos, Mexico.

Author Contributions: Conceptualization: O.G.M.G., F.C.-A. and N.R.; Methodology: O.G.M.G., F.C.-A. and N.R.; Investigation: O.G.M.G., G.S.-R., F.C.-A., L.S.-M. and H.E.F.M.; Resources: F.C.-A. 
and N.R.; Data curation: O.G.M.G.; Writing-Original draft preparation: O.G.M.G., F.C.-A., N.R. and A.J.-P.; Writing-Review and editing: O.G.M.G., F.C.-A., N.R. and A.J.-P. All authors have read and agreed to the published version of the manuscript.

Funding: This research was funded by the National Council of Science and Technology (CONACYT) for the Doctoral grant awarded to the first author and the Research and Graduate Secretariat of the National Polytechnic Institute (SIP-IPN).

Institutional Review Board Statement: Not applicable.

Data Availability Statement: Data sharing is not applicable to this article.

Acknowledgments: The authors thank: CONACYT, SIP-IPN (Projects SIP 2019-5544 and SIP 20194962), the Biotic Products Development Center of the National Polytechnic Institute (CEPROBI-IPN), the International Maize and Wheat Improvement Center-CIMMYT (Tlaltizapán experimental station) and the National Institute for Forestry, Agriculture and Livestock Research-INIFAP (Zacatepec Experimental Field). We also thank the engineer Eliud Pérez Medel, manager of Hub Pacífico Centro-CIMMYT for his support on behalf of CIMMYT and Augustin Miranda for the loan of the experimental area and logistical support during the experiment. FCA, NR, AJP and HFM are COFAA fellows. Finally, we thank the following master's students in Agroecological Management of Pests and Diseases of CEPROBI-IPN (Generation B-2018) for their support during the arduous field work, from the establishment of the experiment to the harvest: Medina Espinosa Ernesto, Pérez García Mariana, Herrera Álvarez Maricela and Diaz Noyola Jorge Enrique.

Conflicts of Interest: The authors declare no conflict of interest.

\section{References}

1. Altieri, M. Bases Científicas Para una Agricultura Sustentable; Editorial Nordan-Comunidad: Montevideo, Uruguay, $1999 ;$ p. 338.

2. Gliessman, S.R. Field and Laboratory Investigations in Agroecology, 3rd ed.; CRC Press: West Palm Beach, FL, USA, $2014 ;$ p. 256.

3. Altieri, M.A.; Funes-Monzote, F.R.; Petersen, P. Agroecologically efficient agricultural systems for smallholder farmers: Contributions to food sovereignty. Agron. Sustain. Dev. 2012, 32, 1-13. [CrossRef]

4. Álvarez, E.; Carreón, A.; San Vicente, A. Haciendo Milpa: La Protección de las Semillas y de la Agricultura Campesina; UNAM: Ciudad de México, Mexico, 2011; p. 104.

5. Chen, Y.H.; Shapiro, L.R.; Benrey, B.; Cibrian-Jaramillo, A. Back to the origin: In situ studies are needed to understand selection during crop diversification. Front. Ecol. Evol. 2017, 5, 1-8. [CrossRef]

6. Jiggins, J. Agroecology: Adaptation and Mitigation Potential and Policies for Climate Change. In Global Environmental Change; Springer: Dordrecht, The Netherlands, 2014; pp. 733-743.

7. Rosset, P.M.; Altieri, M.A. Agroecología Ciencia y Política; Icaria Editorial: Barcelona, Spain, 2018; p. 206.

8. Harrison, R.D.; Thierfelder, C.; Baudron, F.; Chinwada, P.; Midega, C.; Schaffner, U.; Van den Berg, J. Agro-ecological options for fall armyworm (Spodoptera frugiperda JE Smith) management: Providing low-cost, smallholder friendly solutions to an invasive pest. J. Environ. Manag. 2019, 243, 318-330. [CrossRef]

9. D'Annolfo, R.; Gemmill-Herren, B.; Amudavi, D.; Shiraku, H.W.; Piva, M.; Garibaldi, L.A. The effects of agroecological farming systems on smallholder livelihoods: A case study on push-pull system from Western Kenya. Int. J. Agric. Sustain. 2020, 18, 1-15. [CrossRef]

10. Pyke, B.; Rice, M.J.; Sabine, B.; Zalucki, M.P. The push-pull strategy—Behavioural control of Heliothis. Aust. Cotton. Grow. 1987, 8, 7-9.

11. Miller, J.R.; Cowles, R.S. Stimulo-deterrent diversion: A concept and its possible application to onion maggot control. J. Chem. Ecol. 1990, 16, 3197-3212. [CrossRef]

12. Khan, Z.R.; Midega, C.A.O.; Amudavi, D.M.; Hassanali, A.; Pickett, J.A. On-farm evaluation of the 'push-pull' technology for the control of stemborers and striga weed on maize in western Kenya. Field Crop. Res. 2008, 103, 224-233. [CrossRef]

13. Midega, C.A.O.; Pittchar, J.O.; Pickett, J.A.; Hailu, G.W.; Khan, Z.R.A. Climate-adapted push-pull system effectively controls fall armyworm, Spodoptera frugiperda (J. E. SMITH), in maize in east Africa. Crop. Prot. 2018, 105, 10-15. [CrossRef]

14. Khan, Z.R.; Pittchar, J.O.; Midega, C.A.O.; Pickett, J.A. Push-pull farming system controls Fall Armyworm: Lessons from Africa. Outlooks Pest Manag. 2018, 29, 220-224. [CrossRef]

15. Hailu, G.; Niassy, S.; Khan, R.Z.; Ochatum, N.; Subramanian, S. Maize-Legume Intercropping and Push-Pull for Management of Fall Armyworm, Stemborers, and Striga in Uganda. Agron. J. 2018, 110, 1-10. [CrossRef]

16. Guera, O.G.M.; Castrejón-Ayala, F.; Robledo, N.; Jiménez-Pérez, A.; Sánchez-Rivera, G. Plant Selection for the Establishment of Push-Pull Strategies for Zea mays-Spodoptera frugiperda Pathosystem in Morelos, Mexico. Insects 2020, 11, 349. [CrossRef]

17. Climate-Data. Clima: Morelos. Available online: https:/ / es.climate-data.org/ (accessed on 16 June 2019). 
18. Khan, Z.R.; Muyekho, F.N.; Njuguna, E.; Pickett, J.A.; Wadhams, L.J.; Pittchar, J.; Ndiege, A.; Genga, G.; Nyagol, D.; Lusweti, C. A Primer on Planting and Managing 'Push-Pull' Fields for Stemborer and Striga Weed Control in Maize: A Step-by-Step Guide for Farmers and Extension Staff, 2nd ed.; ICIPE Science Press: Nairobi, Kenya, 2007; 60p.

19. Cooke, B.M. Disease assessment and yield loss. In The Epidemiology of Plant Diseases; Springer: Dordrecht, The Netherlands, 2006; pp. $43-80$.

20. Abbott, W.S. A method of computing the effectiveness of an insecticide. J. Econ. Entomol. 1925, 18, 265-267. [CrossRef]

21. Watson, D.J. Comparative physiological studies in the growth of field crops. I. Variation in net assimilation rate and leaf area between species and varieties, and within and between years. Ann. Bot. 1947, 11, 41-76. [CrossRef]

22. Monsi, M.; Saeki, T. On the factor light in plant communities and its importance for matter production. Ann. Bot. 2005, 95, 549-567. [CrossRef]

23. Zamudio-González, B.; Espinosa-Calderón, A.; Tadeo-Robledo, M.; Encastín-Dionicio, J.J.; Martínez, J.N.R.; Felix-Reyes, A.; Cárdenas, M.A.L.; Turrent, F.A. Producción de híbridos y variedades de maíz para grano en siembra a doble hilera. Rev. Mex. Cienc. Agríc. 2015, 6, 1491-1505.

24. Omokanye, A.; Yoder, C.; Sreekumar, L.; Vihvelin, L.; Benoit, M. Forage Production and Economic Performance of Pasture Rejuvenation Methods in Northern Alberta, Canada. Sustain. Agric. Res. 2018, 7, 94-110. [CrossRef]

25. Carrano-Moreira, A.F. Manejo Integrado de Pragas Florestais: Fundamentos Ecológicos, Conceitos e Táticas de Controle; Technical Books: Rio de Janeiro-RJ, Brazil, 2014; p. 349.

26. González-Estrada, A. A Dynamic General Equilibrium Model of Mexico: Macroeconomic Dynamics under NAFTA. Ph.D. Thesis, Graduate School of the University of Minnesota, Minneapolis, MN, USA, 1999.

27. Shapiro, S.S.; Wilk, M.B. An analysis of variance test for normality (complete samples). Biometrika 1965, 52, 591-611. [CrossRef]

28. Levene, H. Robust Tests for Equality of Variances. In Contributions to Probability and Statistics: Essays in Honour of Harold Hotelling; Stanford University Press: Redwood, CA, USA, 1960; pp. 278-292.

29. Gbur, E.E.; Stroup, W.W.; McCarter, K.S.; Durham, S.; Young, L.J.; Christman, M.; West, M.; Kramer, M. Analysis of Generalized Linear Mixed Models in the Agricultural and Natural Resources Sciences; ASA, CSSA, and SSSA: Madison, WI, USA, 2012; 283p.

30. Chen, K.; Cheng, Y.; Berkout, O.; Lindhiem, O. Analyzing Proportion Scores as Outcomes for Prevention Trials: A Statistical Primer. Prev. Sci. 2017, 18, 312-321. [CrossRef]

31. Bates, D.; Mächler, M.; Bolker, B.; Walker, S. Fitting Linear Mixed-Effects Models Using lme4. J. Stat. Softw. 2015, 67, 1-48. [CrossRef]

32. Scott, A.J.; Knott, M. Cluster analysis method for grouping means in the analysis of variance. Biometrics 1974, 30, 507-512 [CrossRef]

33. Jelihovschi, E.G.; Faria, J.C.; Allaman, I.B. ScottKnott: A Package for Performing the Scott-Knott Clustering Algorithm in R. Trends Appl. Comp. Math. 2014, 15, 3-17. [CrossRef]

34. Borges, L.C.; Ferreira, D.F. Poder e taxas de erro tipo I dos testes de Scott-Knott, Tukey e Student-Newman-Keuls sob distribuições normal e não normais dos resíduos. Rev. Mat. Estat. 2003, 21, 67-83.

35. Ferreira, D.F.; Muniz, J.A.; Aquino, L.H. Comparações múltiplas em experimentos com grande número de tratamentos-utilização do teste de Scott-Knott. Cienc. Agrotecnologia 1999, 23, 745-752.

36. Le, S.; Josse, J.; Husson, F. FactoMineR: An R Package for Multivariate Analysis. J. Stat. Softw. 2008, 25, 1-18. [CrossRef]

37. Yanhui Fan, F. FinCal: Time Value of Money, Time Series Analysis and Computational Finance. 2016. Available online: https:/ / mran.microsoft.com/snapshot/2016-08-05/web/packages/FinCal/FinCal.pdf (accessed on 20 August 2020).

38. R Core Team. R: A Language and Environment for Statistical Computing; R Core Team: Vienna, Austria, 2020.

39. Njeru, N.K.; Midega, C.A.O.; Muthomi, J.W.; Wagacha, J.M.; Khan, Z.R. Impact of push-pull cropping system on pest management and occurrence of ear rots and mycotoxin contamination of maize in western Kenya. Plant Pathol. 2020, 69, 1644-1654. [CrossRef]

40. Altieri, M.A. Diversification of corn agroecosystems as a means of regulating fall armyworm populations. Fla. Entomol. 1980, 63, 18-24. [CrossRef]

41. Midega, C.A.O.; Bruce, T.J.A.; Pickett, J.A.; Pittchar, J.O.; Murage, A.; Khan, Z.R. Climate-adapted companion cropping increases agricultural productivity in East Africa. Field Crop. Res. 2015, 180, 118-125. [CrossRef]

42. Midega, C.A.O.; Bruce, T.J.A.; Pickett, J.A.; Khan, Z.R. Ecological management of cereal stemborers in African smallholder agriculture through behavioral manipulation. Ecol. Entomol. 2015, 40, 70-81. [CrossRef]

43. Ndayisaba, P.C.; Kuyah, S.; Midega, C.A.O.; Mwangi, P.N.; Khan, Z.R. Push-pull technology improves maize grain yield and total aboveground biomass in maize-based systems in Western Kenya. Field Crop. Res. 2020, 256, 1-12. [CrossRef]

44. Khan, Z.; Midega, C.; Pittchar, J.; Pickett, J.; Bruce, T. Push-pull technology: A conservation agriculture approach for integrated management of insect pests, weeds and soil health in Africa. Int. J. Agric. Sustain. 2011, 9, 162-170. [CrossRef]

45. Khan, Z.R.; Midega, C.A.O.; Njuguna, E.M.; Amudavi, D.M.; Wanyama, J.M.; Pickett, J.A. Economic performance of 'push -pull' technology for stem borer and striga weed control in smallholder farming systems. Crop Prot. 2008, 27, 1084-1097. [CrossRef] 